\section{No a la automedicación}

Señor editor: A finales del año pasado fue publicado en el suplemento 4 el artículo "Nuevas etiquetas de medicamentos para apoyar la automedicación en México. El caso de un analgésico pediátrico". Nos llama mucho la atención que se difunda una acción de este tipo, sobre todo en una revista de carácter científico y de gran peso en el ámbito de la salud.

Durante décadas, quienes nos dedicamos a la atención de la salud hemos estado en contra de la automedicación, costumbre por demás arraigada en nuestro país, pero combatida por los trabajadores de la salud; incluso cuando enferma un médico recomendamos sea atendido por otro médico, para con ello no contribuir a la automedicación.

Consideramos que el artículo es un buen trabajo en cuanto a diseño y metodología empleada, y que señala de manera puntual algunos aspectos socioculturales y riesgos de los usuarios directos, expuestos a la práctica de la automedicación en México, dado el alto índice de analfabetas funcionales y la escasa cultura de dar lectura a los instructivos e indicaciones del uso de los productos que compramos y consumimos. Esto es por un lado, y por otro está la irresponsabilidad de las compañías farmacéuticas por no contar con un responsable del manejo y distribución de los mismos.

Sin duda alguna que la mercadotecnia y la modernidad ha venido a promover la mala costumbre de automedicarse; hoy en día gran cantidad de medicamentos se encuentran al alcance de todos, en farmacias y tiendas de autoservicio.

Pero jamás se justificará el fomento a la automedicación; por el contrario, se debería desalentar para proteger la seguridad del consumidor a los eventos adversos de los mismos, premisa responsable y fundamental que toda la industria farmacéutica en México debería de tener.

No estamos en contra de que las etiquetas sean más explícitas, y qué bueno que se sugiere claridad en los términos sin embargo, la intención, tal y como se menciona en el artículo en cuestión, no solucionará el problema de la automedicación.

La automedicación es una mala costumbre que en ocasiones puede causar la muerte. Los medicamentos de libre acceso no están libres de reacciones secundarias y contraindicaciones, mismas que sólo el facultativo, con el conocimiento de farmacología y fisiología, puede entender y prever.

El mismo ácido acetilsalicílico, con todas sus bondades, tiene una gran cantidad de contraindicaciones y reacciones adversas que pueden llevar a agravar un síntoma. Es por ello que insistimos mucho en que todo medicamento sea expedido sólo con receta médica.

Conclusión: nos parece un buen intento el mejorar las etiquetas sobre información de los productos elaborados en la industria farmacéutica de nuestro país, además de agregar con letras grandes los tres efectos colaterales más frecuentes que ayuden a las personas que, por su decisión y riesgo propio, decidan automedicarse, pero jamás fomentar o apoyar la automedicación en nuestro país, como los sugiere la propuesta del título de este estudio en cuestión.

$$
\begin{array}{r}
\text { CD Ma. Esther Hernández Martínez, }{ }^{(I)} \\
\text { Dra. Maria Luisa Cárdenas Castillo, }{ }^{(I)} \\
\text { CD Rocío Laguna Legorreta, }{ }^{(I)} \\
\text { Lic. en Enf. Edith Ochoa Chávez, }{ }^{(I)} \\
\text { Dra. Lili Elguezabal Rodríguez, }{ }^{(I)} \\
\text { CD Francisco Javier Vázquez Santana, }{ }^{(I)} \\
\text { Dr. Leopoldo Contreras Gómez, }{ }^{(I)} \\
\text { Dr. Guillermo Zenteno Covarrubias. }{ }^{(I)} \\
\text { zenteno_gmo@yahoo.es }
\end{array}
$$

(I) Grupo de Investigación de la Región Sanitaria X, de la Secretaría de Salud Jalisco 